\title{
Design and Manufacturing of Plastic Scrubber / Bullet Assembly Machine
}

\author{
Vineet Kadam $^{1}$, Jitendra Kumar ${ }^{2}$, Prashant Sharma ${ }^{3}$ \\ ${ }^{1,2,3}$ University of Pune, Department of Mechanical Engineering, DYPIEMR, Akurdi Pune -411044, India
}

\begin{abstract}
The project on 'Design, Analysis \& Manufacture of Plastic Bullet Assembly Machine' is being created with the prime motive of optimization of labour and cost. Also the bar of precision and accuracy has been extended to mere perfection with the help of this semi-automated machine. The method is simple and easy to understand. In this, the assembly of bullet is done with the help the machine that is similar to a press machine. The assembly is done with the help of compressed air which is provided by the pneumatic cylinder. An indexing mechanism is provided for the necessity of the bullet assembly. Also the chuck is so designed that it can be handled with ease by the operator, which is convenient and time saving. Hence the assembly machine is compact in size and is portable. It is easy to assemble the products now for the operator and has optimized labour cost. This has also given rise to fast, smooth \& tidy work.
\end{abstract}

Keywords: Chuck, adon block and rail, pneumatic cylinder, bullet/scrubber, DCV (Tandem Centre).

\section{Introduction}

Scale formation in the tubes is a common problem faced by industries using boilers, condensers, heat exchanger and rest fluid transporting devices. There is a vast use of chemicals for the cleaning purpose but it in turn also corrodes the inner surfaces. Hence a plastic bullet firing in the tubes is a safer alternative that is being started these days. Presently as the bullet assembly is done manually, due to increasing demands it has become a necessity to optimize the assembly.

\section{How are Boiler and condenser tubes cleaned with these Scrubber/bullets?}

The scrubber/bullet is made up of three copper flanges, three plastic bushes, a P.V.C. rod and a plastic crown. the size of the bullet, the size of the P.V.C. rod and copper flanges varies with the size of boiler or the condenser tubes. The semi-automatic assembly machine that is discussed in the paper is so designed to clean the boiler tubes having inner diameter $30 \mathrm{~mm}$. The flange of copper having grade name 27 are used in these bullets.

The P.V.C. rod is of hexagonal cross section and is $65 \mathrm{~mm}$ long. There are hexagonal slots on the copper flanges of the same size as that of the P.V.C. rod. The three copper flanges are to be placed at $120^{\circ}$ apart from each other and the plastic bullets go in between them. Hence by having three flanges at 120 degrees each the whole $360^{\circ}$ of circular cross section of the tubes can be cleaned. The plastic crown goes in the end so as to lock the bushes and the flanges and is riveted at the end. The end product is shown in the figure no. 1
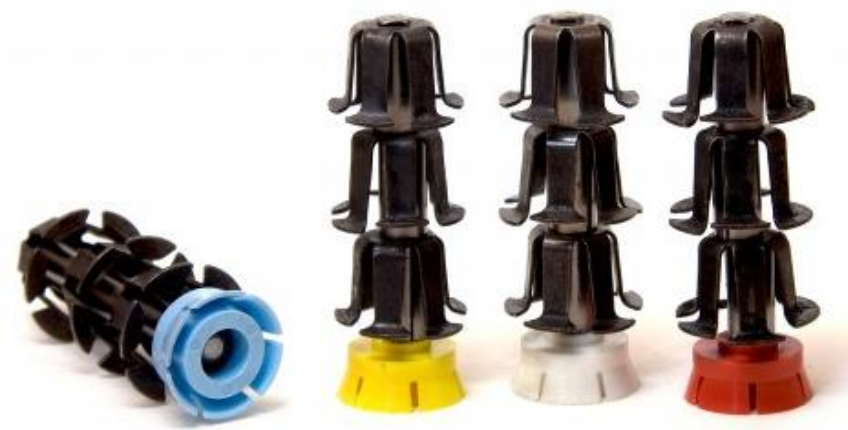

Figure 1: End product bullet/scrubber

These bullets are loaded in the boiler tubes and are forced inside using water pressure. The pressure usually ranges from 6.89 bar to 20.68 bar (i.e. 100 psi to 300 psi). Due to this pressure the scrubbers are forced inside the tubes and hence they move forward with swirling action. The clearance between the copper flanges and the inner diameter of the tubes is in microns. Hence any deposited scales are removed off due to friction and scraping action of the bullets. As there is no contact with the tubes it does not harm them.

\section{Design of the assembly machine}

\subsection{Double Acting pneumatic cylinder}

An (pneumatic) air cylinder is an operative device in which the state input energy of compressed air; (i.e.) pneumatic power is converted into mechanical output power, by reducing the pressure of the air to that of the atmosphere. The bore of the cylinder has very smooth finishing reduces friction and losses. There are two angle plates welded to the cylinder as fitting means. A double acting cylinder is employed in a control system with a full pneumatic cushioning and it is essential when the cylinders itself is required heavy masses. The normal escape of air is out by 'cushioning piston'. 


\section{International Journal of Science and Research (IJSR) \\ ISSN (Online): 2319-7064}

Index Copernicus Value (2013): 6.14 $\mid$ Impact Factor (2015): 6.391

\subsection{Directional control valve with tandem centre}

Directional control valves are one of the most fundamental parts in hydraulic machinery as well as pneumatic machinery. This valve is used to control the direction of air flow in the pneumatic system. They allow fluid flow into different paths from one or more sources. They usually consist of a spool inside a cylinder which is mechanically or electrically controlled. The movement of the spool restricts or permits the flow, thus it controls the fluid flow.

\subsection{Flow control valve}

The flow control valve is used to control the flow of air into the cylinder. In this machine we have used flow control valve to control the forward and return stroke of cylinder.

\subsection{Drill chuck}

Chuck is a specialized type of clamp. It is used to hold an object with radial symmetry, especially a cylinder. In drills and mills it holds the rotating tool whereas in lathes it holds the rotating work piece. On a lathe the chuck is mounted on the spindle which rotates within the headstock. For some purposes (such as drilling) an additional chuck may be mounted on the non-rotating tailstock. In our project we have three jaw chuck which is a type of drill chuck. Now the purpose of using this type of chuck is the time saving goal which is necessary in the optimization process. This chuck can be easily operated with the help of our hand and a key the procedure is simple. The chuck is being used for holding the non-ferrous materials like the copper, bronze, aluminium, titanium, plastics, and stone. The drill chuck is used as it has good holding capacity for small cross section rod and can be easily tightened using a key.

\subsection{Filters, Regulators, And Lubricators (FRL) unit}

Pneumatic actuators and controls perform more reliably and efficiently, and have a longer life, when the air is prepared for your specific application. These easy-to-use FRLs are specifically engineered to give you increased airflow from a modular system.

\subsection{Adon and Rail}

Adon block is used to maintain alignment between chuck and hexagonal die and rail guides the adon block.

\subsection{Indexing Mechanism}

In our assembly machine we have an indexing mechanism which is has three holes on the circumference known as dimple. Now the dimples are set in such a way that the when the head is being rotated it should be locked at 120 degrees. The indexing mechanism has hexagonal hole dye at the top which is having the same shape as that of the flange. Hence the flange and P.V.C rod could be kept accurately on the dye. The indexing mechanism shown in figure 2 .

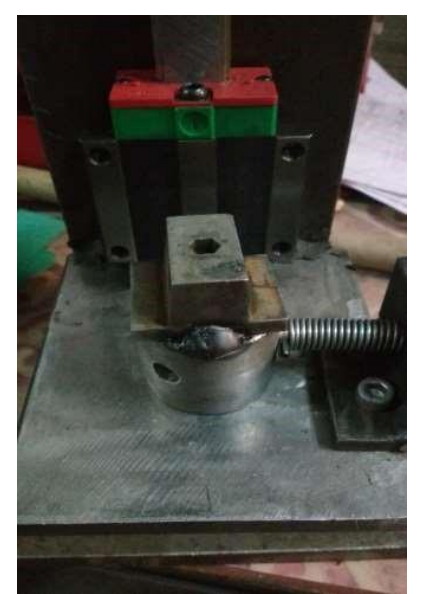

Figure 2: Indexing Mechanism

\subsection{Compressor}

The compressor is one of the main part of the pneumatic system. Compressor capacity is the actual quantity of air compressed and delivered and the volume expressed is that of the air intake conduction, normally at atmospheric pressure and normal ambient temperature. The clear conduction of the suction air is one of the factors which decide the life of a compressor. Compressor is generally classified into two types, namely.

1) Positive displacement compressor

2) Turbo compressor

\section{Working}

The assembly machine designed works on the principal similar to that of a press machine. First the copper flange is kept on the die. Then the P.V.C. rod is mounted inside the die which has a hexagonal hole. The chuck is in the closed position and the first stroke is applied. This is done so that the copper flange goes into the P.V.C. rod up to the final most point. Placing the P.V.C. rod inside a hexagonal hole fixes the constrain that would lead to improper alignment of degree. now the chuck is slowly brought down by the worker by controlling the DCV valve and the flow control valves, the P.V.C. rod in that position is inserted in the chuck and the chuck is closed by the operator using a key. The operator inserts a bush inside. The assembly is taken up again by the DCV valve in the up stroke. Now the next flange is carefully kept on the die and the first rotation is given to the indexer.

By pulling the dowel pin by one hand and rotating the indexer till it gets locked in the next dimple. a down stroke is applied now. The chuck in which the P.V.C. rod is held is forced into the die be the pneumatic force exerted by the cylinder. The downward movement i.e. the down stroke is slow and the upward movement or the up stroke is quick. This quick return is for two purposes. First is because the time of return or idle time is to be reduced. Secondly the quick return helps in separating the flange from the die. Now the bush of plastic is inserted into the P.V.C. rod. The dowel pin which is used to lock the indexing mechanism is now pulled and the indexing mechanism is rotated by 120 i.e. up to the point till when the dowel pin is locked in the next hole or the dimple. The three dimples are provided on the

Volume 5 Issue 6, June 2016 www.ijsr.net 


\section{International Journal of Science and Research (IJSR) \\ ISSN (Online): 2319-7064 \\ Index Copernicus Value (2013): 6.14 | Impact Factor (2015): 6.391}

circumference of the indexer so as to get $100 \%$ accurate degrees at the dimples. Now the second flange of copper is kept on the die and the similar procedure is applied. At last after the three flanges and bushes are inserted the P.V.C. rod is removed and the crown is attached and riveted. The whole procedure is done by a single worker.

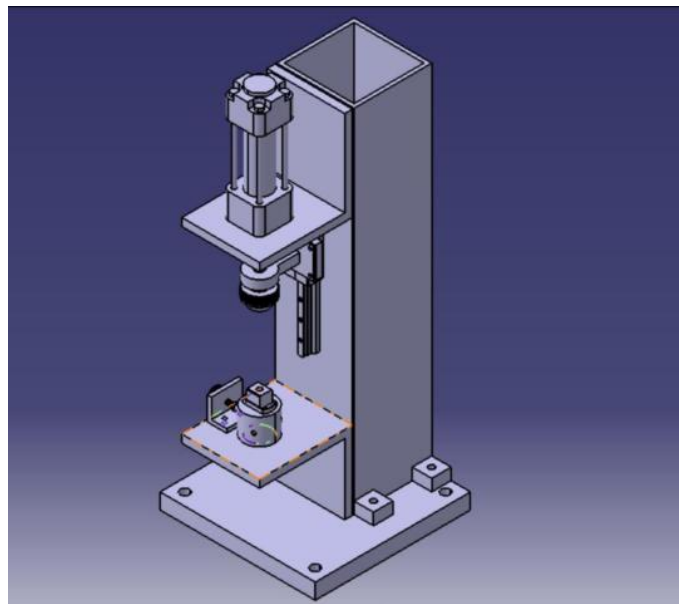

Figure 3 :(Catia model of assembly machine)

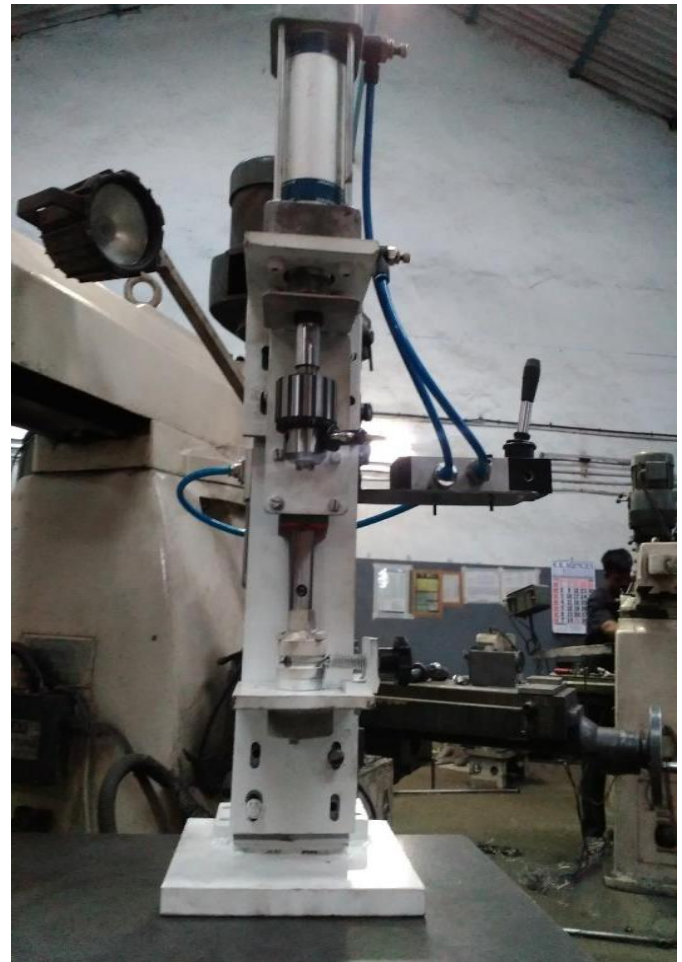

Figure 4: (Manufactured assembly machine)

\section{Optimized Parameter}

With the making of machine, the optimization of different parameter as shown Table1.

Table 1

\begin{tabular}{|c|c|c|c|}
\hline Sr. No. & Parameter & Before & After \\
\hline 1 & No of workers required & 3 & 1 \\
\hline 2 & Manufacturing time & 4 min & 2 min \\
\hline 3 & Accuracy & Low & High \\
\hline 4 & Faulty production & More & Almost zero \\
\hline 5 & Worker fatigue & More & Less \\
\hline 6 & Worker safety & Less & More \\
\hline
\end{tabular}

\section{Conclusion}

The total time needed for completion of one part manually was about $4 \mathrm{~min}$. three workers were needed and the work was tedious and stressful. After the assembly machine is installed the time needed for assembly is $2 \mathrm{~min}$ hence there is $50 \%$ save in time. The workers needed were 3 which has reduced to a single worker. As there is no need of three workers the single worker who is working can independently take the decisions and actions regarding the working and manufacturing. The work has become much more easy and interesting. The cost of worker is reduced. There is accurate decision regarding the indexing. Hence the scrape has reduced. The accuracy and precession in the work has increased.

\section{Future Scope}

By changing the DCV valve and giving limit switch the time of applying the force can be reduced. The chuck can be replaced by automatic clamping devices which would clamp the P.V.C. rod automatically. This all in turn would increase the capital cost but later reduce the time of production to a larger extent and the assembly would be fully automatic. This would also reduce worker cost to zero.

\section{References}

[1] S. R. Pandian,Y. Hayakawa,Y. Kanazawa et al,Practical design of a sliding mode controller for pneumatic actuators, Transactions of the ASME,Journal of Dynamic systems, Measurement and Control,vol.119,no.4,1997,pp 666-674.

[2] "Ming-Hung Tsai", "Design And Control For The Pneumatic Cylinder Precision Positioning Under Vertical Loading".

[3] "Robert B. van Varseveld and Gary M. Bone"," Accurate Position Control of a Pneumatic.

[4] “A. ILCHMANN"," Pneumatic cylinders: modelling and feedback force-control". International Journal of Control Vol. 79, No. 6, June 2006, 650-661.

\section{Author Profile}

Vineet Kadam is currently perusing B.E degree in mechanical engineering from Pad. Dr. D. Y. Patil Institute of Engineering, Management \& Research, Akurdi, Pune, Maharashtra, India

Jitendra Kumar is currently perusing B.E degree in mechanical engineering from Pad. Dr. D. Y. Patil Institute of Engineering, Management \& Research, Akurdi, Pune, Maharashtra, India

Prashant Sharma is currently perusing B.E degree in mechanical engineering from Pad. Dr. D. Y. Patil Institute of Engineering, Management \& Research, Akurdi, Pune, Maharashtra, India 